\title{
Mediating Effects of Aryl-Hydrocarbon Receptor and RhoA in Altering Brain Vascular Integrity
}

\section{The Therapeutic Potential of Statins}

\author{
Chih-Cheng Chang, ${ }^{* \dagger}$ Pei-Shan Lee, ${ }^{* \dagger}$ \\ Ying Chou, ${ }^{* \dagger}$ Ling-Ling Hwang, ${ }^{* \dagger}$ and \\ Shu-Hui Juan* ${ }^{\dagger}$ \\ From the Graduate Institute of Medical Sciences* and the \\ Department of Physiology, School of Medicine, College of Medicine, \\ Taipei Medical University, Taipei, Taiwan
}

We have demonstrated previously that focal adhesion kinase (FAK)/RhoA alteration by the aryl-hydrocarbon receptor (AhR) agonist 3-methylcholanthrene (3MC) is involved in the antimigratory effects of $3 \mathrm{MC}$ in human umbilical vascular endothelial cells. Here, we identified that signaling properties and molecular mechanisms of RhoA/ $\boldsymbol{\beta}$-catenin were both implicated in alterations to blood-brain barrier integrity. The mechanisms of action were the down-regulation of integrin, the extracellular matrix, and adherens junction stability. PTEN phosphorylation by 3MC-mediated AhR/RhoA activation increased the proteasomal degradation of $\beta$-catenin through $\mathrm{PKC} \delta /$ pGSK3 $\beta$-mediated $\beta$-catenin phosphorylation; the crucial roles of $A h R / R h o A$ in this process were verified by using gain- or loss-of-function experiments. The decrease in $\beta$-catenin led to decreased expression of fibronectin and $\alpha 5 \beta 1$ integrin. Additionally, protein interactions among FAK, VE-cadherin, vinculin, and $\beta$-actin were simultaneously decreased, resulting in adherens junction instability. Novel functional TCF/LEF1 binding sites in the promoter regions of fibronectin and $\alpha 5 / \beta 1$ integrin were identified by electrophoretic mobility shift and chromatin immunoprecipitation assays. The results indicate that the binding activities of $\beta$-catenin decreased in mouse cerebrovascular endothelial cells treated with 3MC. In addition, simvastatin and pravastatin treatment reversed $3 \mathrm{MC}$-mediated alterations in mouse cerebrovascular endothelial cells by RhoA inactivation, and the in vitro findings were substantiated by an in vivo bloodbrain barrier assay. Thus, endothelial barrier dysfunction due to 3MC occurs through AhR/RhoA-mediated $\beta$-catenin down-regulation, which is reversed by simva- statin treatment in vivo. (Am J Pathol 2012, 181:211-221;

http://dx.doi.org/10.1016/j.ajpath.2012.03.032)

Endothelial cells act as a semipermeable barrier to circulating macromolecules and biological chemicals. Endothelial barrier integrity is maintained by the adhesive interactions of cell-cell and cell-matrix contacts, through junctional proteins and focal adhesion complexes that are anchored to the cytoskeleton. ${ }^{1}$ Vascular endothelial cells in the central nervous system form a blood-brain barrier (BBB) to restrict the movement of ions and molecules between the blood and brain. Disruption of the BBB in central nervous system injury and diseases can lead to neuroinflammation. Previous research has shown that murine cerebrovascular endothelial cells (MCVECs) and astrocytes respond to 2,3,7,8-tetrachlorodibenzo-p-dioxin (TCDD) through an aryl-hydrocarbon receptor (AhR)-mediated pathway, and may then become targets of toxicity. ${ }^{2}$

Focal adhesions and the extracellular matrix environment are crucial for endothelial cells to grow and organize into functional vascular networks during development and angiogenic blood vessel formation. ${ }^{3}$ Focal adhesions are composed of transmembrane receptors, integrins, and intracellular proteins that link integrins to the cytoskeleton. Integrins function as adhesion receptors for the extracellular matrix, both of which transmit chemical signals and mechanical forces that regulate cellular functions. Various integrins with distinct combinations of $\alpha$ and $\beta$ subunits have been identified in endothelial cells. ${ }^{4}$ Because of a lack of catalytic activity of integrins, signals are transduced via a network of integrin-associated proteins. ${ }^{5}$ The focal adhesion complex contains a group of signaling molecules, including focal adhesion kinase (FAK), Src tyrosine kinases, and Rho GTPases, all of which are known to be in-

Supported by grants [NSC97-2320-B-038-017-MY3 and NSC100-2320-B038-016-MY2(2-2)] from the National Science Council of Taiwan.

Accepted for publication March 19, 2012.

Address reprint requests to Shu-Hui Juan, Ph.D., Graduate Institute of Medical Sciences and Department of Physiology, Taipei Medical University, 250 Wu-Hsing St, Taipei 110, Taiwan. E-mail: juansh@tmu.edu.tw. 
volved in endothelial contractile morphology and barrier responses. ${ }^{6}$ Fibronectin, a dimeric glycoprotein of 440 to 560 $\mathrm{kDa}$, serves as a multidimensional fibrillar matrix, and the architecture of the network itself contributes to the control of cell behavior. $^{7}$

The Rho family of GTPases, including Rho, Rac, and Cdc42, has been identified as consisting of signaling molecules that regulate cytoskeletal rearrangement. These molecules are involved in cellular functions, including smooth muscle cell contraction and cell migration. Rac and Cdc42, respectively, regulate lamellipodia and filopodia formation at the leading edge of the migrating cell, whereas Rho is required to form and maintain focal adhesions. ${ }^{8}$ A focal adhesion assembly, a process of cell motility, leads to the organization of an actin-containing cytoskeleton, and its associated proteins are tyrosine phosphorylated and enzymatically activated, which could lead to disruption of the organization of focal contacts and thus cause loose cell substratum adhesion..$^{9,10}$ Research has reported on the roles of RhoA in regulating gene expression and cell proliferation. ${ }^{11}$ All RhoA-regulated cellular functions are important in the pathogenesis of vascular disease. Moreover, recent studies by our group and others have demonstrated that RhoA, through its downstream effector Rho kinase (ROCK), activates myosin light chain (MLC) phosphorylation, either by activating MLC kinase or by inactivating MLC phosphatase. ${ }^{12,13}$ Activation of MLC results in an increase in actomyosin-based contractility, which is important for cell migration. ${ }^{14}$

Recent reports have emphasized the importance of adherens junctions as a major component in the pathophysiological regulation of paracellular permeability of the microvascular endothelium. This is despite the wellknown role of tight junctions in maintaining the BBB. Vascular endothelial (VE)-cadherin, the primary component of adherens junctions, contacts adjacent endothelial cells through a calcium-dependent homophilic binding of its extracellular domain. By contrast, the intracellular domain of VE-cadherin interacts with the actin cytoskeleton via catenins. ${ }^{15}$ The extracellular binding between two VE-cadherin molecules mainly affects initial cell-cell contacts during vessel development, and their cytoskeletal interaction with catenins is important in maintaining junctional strength and paracellular permeability. ${ }^{15,16}$ Dissociation of the VE-cadherin-catenin complex from the cytoskeleton has been found to cause endothelial barrier dysfunction. ${ }^{17,18}$ Such disorganization is mainly mediated by $\beta$-catenin, which is noted for its roles in structural linkages between VE-cadherin and other catenins, and also in signal transduction of junction-cytoskeletal interactions. ${ }^{19,20}$ The phosphorylation status of $\beta$-catenin promotes the dissociation of junctional proteins from their cytoskeletal anchors, resulting in decreased cell-cell adhesive strength. ${ }^{18,20}$ The amino terminal domain of $\beta$-catenin contains a highly conserved consensus sequence for phosphorylation by glycogen synthase kinase (GSK)3 $\beta$. This phosphorylation leads to degradation of $\beta$-catenin by proteasomes, whereas the carboxyl terminal domain of $\beta$-catenin is essential for transcriptional activity. Complex formation between $\beta$-catenin and proteins of T-cell factor/lymphocyte enhancement factor (TCF/LEF) family has been shown to increase the induction of trans- activating target genes including MYC (alias C-MYC), ${ }^{21}$ PPAR $\delta,{ }^{22}$ and CCND1 (cyclin D1). ${ }^{23}$

Simvastatin and pravastatin are derivatives of statin. They inhibit 3-hydroxy-3-methylglutaryl-coenzyme A (HMG-CoA) reductase, which blocks the synthesis of isoprenoids and thus inhibits lipid attachment to Rho and its subsequent membrane translocation and activation. Lipid-lowering drugs are used to prevent and treat cardiovascular diseases. However, simvastatin and pravastatin also exert effects not related to the lowering of lipids, which have been implicated in the treatment of glucose-stimulated vascular smooth muscle cell migration ${ }^{24}$ and thrombintriggered vascular responses ${ }^{25}$ by inhibiting RhoA activity. Prior research has identified the dependence of RhoA activation in the antimigratory effects of $3 \mathrm{MC}$ in human umbilical vascular endothelial cells (HUVECs)..$^{13}$ We thus evaluated the use of simvastatin and pravastatin as therapeutic approaches to prevent AhR agonist-mediated vascular endothelial alterations.

We previously reported that $3 \mathrm{MC}$ decreased HUVEC proliferation via p21 and p27 induction ${ }^{26}$ and also altered FAK/ RhoA activation in eliminating cell adhesion and migration. ${ }^{13,27}$ In the current study, we illustrate the molecular mechanism of AhR/RhoA-mediated alterations in brain vascular integrity due to $3 \mathrm{MC}$ and therapeutic intervention with simvastatin. Our research used in vivo assays of BBB integrity.

\section{Materials and Methods}

\section{MCVEC Primary Cultures and Reagents}

MCVECs were prepared as described previously, ${ }^{28}$ with minor modification. MCVECs migrating from vessels were pooled to form a proliferating cell culture that was maintained in Dulbecco's modified Eagle's medium. The medium contained high glucose and L-glutamine levels supplemented with $10 \%$ fetal bovine serum, $0.5 \mathrm{mg} / \mathrm{mL}$ heparin, and $75 \mathrm{mg} / \mathrm{mL}$ endothelial cell growth supplements. Dulbecco's modified Eagle's medium, fetal bovine serum, and tissue culture reagents were obtained from Life Technologies (Gaithersburg, MD). Other reagents were purchased from the following sources: $3 \mathrm{MC}$ from Supelco (Bellefonte, PA); YS-49, Mg132, simvastatin, and pravastatin from Sigma-Aldrich (St. Louis, MO); and wortmannin, rottlerin, and Y27632 from Calbiochem (San Diego, CA).

\section{Preparation of Cell Fractions (Nuclear, Cytosolic, and Membrane) and Western Blot Analysis}

MCVECs were harvested in 6- $\mathrm{cm}^{2}$ dishes after the indicated treatment. The cells were partitioned into cytosolic and nuclear fractions using NE-PER nuclear extraction reagents (Pierce, Rockford, IL) with the addition of protease inhibitors according to the manufacturer's instructions. To prepare membrane-cytosolic fractions, after treatment, the cells were collected and incubated in $0.1 \mathrm{~mL}$ of hypotonic buffer [10 mmol/L Tris ( $\mathrm{pH} 7.5$ ), $0.5 \mathrm{mmol} / \mathrm{L}$ EDTA, and $2 \mathrm{mmol} / \mathrm{L}$ phenylmethylsulfonyl fluoride] at $4^{\circ} \mathrm{C}$ for 30 minutes. After centrifugation, the supernatant (cytosolic fraction) was collected, and the pellet was resuspended in $0.1 \mathrm{~mL}$ of 
radio-immunoprecipitation assay buffer and incubated at $4^{\circ} \mathrm{C}$ for 30 minutes. The resulting fractions were sheared 100 times through an insulin syringe with a 29-ga needle. After centrifugation, the supernatant (membrane fraction) was collected for analysis. Cell lysates $(30 \mu \mathrm{g})$ were electrophoresed on a $10 \%$ sodium dodecylsulfate-polyacrylamide gel and then transblotted onto a Hybond-P membrane (GE Healthcare, Hong Kong, China). The assay included the following antibodies: for $\mathrm{pGSK} 3 \beta, \mathrm{p} \beta$ catenin, and $\beta$-catenin (Cell Signaling Technology, Beverly, MA); for PKC $\delta$, PTEN, RhoA, GAPDH, and Lamin A/C (Santa Cruz Biotechnology, Santa Cruz, CA); for VE-cadherin and vinculin (Sigma-Aldrich); for $\alpha 5 \beta 1$ integrin and fibronectin (Chemicon, Temecula, CA); for AhR (Biomol Research Laboratories, Plymouth Meeting, PA), and for PPTEN (Epitomics, Burlingame, CA). Subsequent procedures are described elsewhere. ${ }^{29}$

\section{Transfection of AhR siRNA and RhoA Variants}

An AhR small interfering RNA (siRNA) (5'-UUACUAUCUUGAAAGAGCCdCdT-3') duplex was chemically synthesized by Ambion (Austin, TX). MCVECs were seeded in six-well plates and transfected with either 100 pmole of AhR siRNA, scrambled control siRNA (\#4611; Ambion), or GAPDH siRNA (\#4624; Ambion) in a 100- $\mu \mathrm{L}$ volume with siPORTNeoFX. RhoA complementary DNAs (cDNAs) [T19N dominant negative (DN) and Q63L constitutive active (CA)] in pUSEamp were purchased from Millipore (Burlington, MA). We transfected the pcDNA-overexpressing variants ( $4 \mu \mathrm{g} / 3.5-\mathrm{cm}$ Petri dish) using jetPEI (Polyplus-Transfection, San Marcos, CA) into MCVECs. After transfection, cells were plated in Dulbecco's modified Eagle's medium with 10\% fetal bovine serum. Levels of RhoA variants were analyzed by Western blotting, and their effects on the transcriptional regulation of fibronectin and $\alpha 5 \beta 1$ integrin were analyzed by an RT-PCR analysis.

\section{RT-PCR Analysis}

Total RNA was prepared from cultures of MCVECs by directly lysing cells in TRIzol buffer (Life Technologies), and mRNAs were reversed transcribed into cDNA using an oligo-dT primer by reverse transcriptase (Invitrogen). The PCR was performed with specific primers, namely, 5'AAGGACAACCGAGGAAACCT-3' and 5'-GCTTGTTTCCTTGCGACTTC-3' for fibronectin, 5'-CAAGGTGACAGGACTCAGCA-3' and 5'-GCTGCAGACTACGGCTCTCT-3' for $\alpha 5$ integrin, 5'-TCACAATGGCACACAGGTT-3' and 5'-GCCAGGGCTGGTTATACAGA-3' for $\beta 1$ integrin, and $5^{\prime}$-ACCACAGTCCATGCCATCAC-3' and 5'-TCCACCACCCTGTTGCTGTA-3' for GAPDH.

\section{Fluorescence Microscopy}

Cells grown overnight on glass coverslips were either treated with $100 \mathrm{nmol} / \mathrm{L}$ of $3 \mathrm{MC}$ for 1 hour or were treated with dimethyl sulfoxide. Thereafter, the cells were washed once with cold phosphate-buffered saline (PBS) and fixed for 10 minutes in $4 \%$ paraformaldehyde. Cells were then permeabilized by treatment with $0.1 \%$ Triton $\mathrm{X}-100$ and $0.05 \%$ Tween 20 in PBS. Coverslips were blocked in $10 \%$ goat serum at room temperature for 1 hour, then stained with an anti- $\beta$-catenin or anti- $\alpha 5 \beta 1$ integrin antibody (Sigma-Aldrich) in a 1:100 dilution overnight at $4^{\circ} \mathrm{C}$, followed by Texas Red-conjugated goat anti-mouse (Jackson ImmunoResearch Laboratories, West Grove, PA) at 1:100 for 60 minutes at room temperature. Coverslips were then mounted on slides with VECTASHIELD Anti-Fade (Vector Laboratories, Burlingame, CA) diluted 1:1 with PBS. Images of MCVECs were obtained with a DMI 6000B CS laser confocal microscope (Leica, Heidelberg, Germany) using an HCX PL APO I-blue $63 \times / 1.40$ to 0.60 NA oil-immersion objective lens. Images were acquired with a CM350 CCD camera (Applied Precision, Issaquah, WA) using the TCS SP5 confocal spectral microscope imaging system software (Leica) and were processed with Photoshop 7.0 software (Adobe Systems, San Diego, CA).

\section{Electrophoretic Mobility Shift Assay and Chromatin Immunoprecipitation Analysis}

The electrophoretic mobility shift assay was performed as described previously, ${ }^{30}$ with minor modifications. To prepare the nuclear protein extracts, MCVECs were placed in $10-\mathrm{cm}^{2}$ dishes and treated with $100 \mathrm{nmol} / \mathrm{L}$ of $3 \mathrm{MC}$ for 1 hour. Thereafter, the MCVECs were subjected to NEPER nuclear extraction reagents (Pierce Biotechnology, Thermo Fisher Scientific, Rockford, IL) with the addition of protease inhibitors. Subsequent procedures for the nuclear protein extraction followed the manufacturer's instructions. Sequences of the oligonucleotides used were 5'-TCTTTACATCAATAAAGATA-3' and 5'-TCTTGCCCGACCGAAAGCGA-3' for the putative TCF/LEF1 wild type and mutant of fibronectin, 5'-AGCATCCTTTGATGAGTGTG-3' and 5'-ATCATCAGGGTCTGAGGTTG-3' for the putative TCF/LEF1 wild type and mutant of $\alpha 5$ integrin, and 5'-GCTGTCTTTGAACACATTTG-3' and 5'GAGGTAGGGTCACACAGGGT-3' for the TCF/LEF1 wild type and mutant of $\beta 1$ integrin, respectively (the conserved and mutated sequences are shown as underlining and bold, respectively). The oligonucleotides were endlabeled with biotin according to the manufacturer's protocol (Pierce Biotechnology). Briefly, unlabeled oligonucleotides ( $1 \mu \mathrm{mol} / \mathrm{L})$ were incubated in TdT reaction buffer containing biotin-11-dUTP $(0.5 \mu \mathrm{mol} / \mathrm{L})$ and TdT $(0.2 \mathrm{U} / \mu \mathrm{L})$ at $37^{\circ} \mathrm{C}$ for 30 minutes. Then $2.5 \mu \mathrm{L}$ of EDTA [0.2 mol/L, $(\mathrm{pH}$ 8.0)] was added to stop each reaction, and $50 \mu \mathrm{L}$ of chloroform/isoamyl alcohol was added to extract the TdT. Extracted nuclear proteins $(10 \mu \mathrm{g})$ were incubated with biotinlabeled $(1 \mathrm{pmol})$ probes at $15^{\circ} \mathrm{C}$ for 30 minutes in a binding buffer containing $1 \mu \mathrm{g}$ of poly deoxyinosine-deoxycytidine (dl-dC) (Panomics, Redwood City, CA). For competition with unlabeled oligonucleotides, a 100-fold molar excess of unlabeled oligonucleotides relative to biotin-labeled probes was added to the binding assay. The mixture was separated on a $6 \%$ nondenaturing polyacrylamide gel at $4^{\circ} \mathrm{C}$ in $1 \times \mathrm{TBE}$ [90 mmol/L Tris borate and $2 \mathrm{mmol} / \mathrm{L}$ EDTA (pH 8.3)] and then transblotted onto a Hybond $\mathrm{N}^{+}$membrane (Amersham Pharmacia Biotech, Freiburg, Germany). Blots were incubated with blocking buffer, followed by additional streptavidin-horserad- 
ish peroxidase conjugates. Blots were imaged by means of an enhanced chemiluminescence system.

Chromatin immunoprecipitation (ChIP) assay was performed according to the instructions of Upstate Biotechnology (Lake Placid, NY) with minor modifications. Briefly, $6 \times 10^{5}$ cells cultured with the indicated treatments in $100-\mathrm{mm}$ dishes were harvested. The resulting supernatant was subjected to overnight co-immunoprecipitation (co-IP) using an anti- $\beta$-catenin antibody. DNA filtrates were amplified by PCR with primers flanking the promoter of fibronectin $\alpha 5$ and $\beta 1$ genes containing the putative $\beta$-catenin-TCF/LEF1 binding sites: fibronectin forward primer 5'-AACCCTGAGTGTTGGTCACA-3' and reverse primer 5'TCCAAGAACCTGGTACAAACAA- $3^{\prime} ; \alpha 5$ forward primer $5^{\prime}$ CAGGCAACTTCTATTCATTCTCTC- $3^{\prime}$ and $\alpha 5$ reverse primer 5'-CAGGCAACTTCTATTCATTCTCTC-3'; and $\beta 1$ forward primer $5^{\prime}$-TGCATGTGCACTAGACTGGA-3' and $\beta 1$ reverse primer 5'-CAGGCAACTTCTATTCATTCTCTC-3'. Additionally, the template was replaced with double-distilled (dd) $\mathrm{H}_{2} \mathrm{O}$ as a negative internal control. PCR products were electrophoresed on a $2 \%$ agarose gel, and PCR products of the expected sizes of 219, 176, and 151 bp were visualized and quantified using an Image analysis system.

\section{Assay of the BBB Integrity}

Animal care and treatment conformed to protocols of the Animal Center, Taipei Medical University. Male Balb/c mice ( 8 weeks old, each weighing 20 to $25 \mathrm{~g}$ ) were used in this study. The mice were fed a regular chow diet and were maintained under conventional housing conditions in our animal facility. We divided the mice into four groups, with group 1 being the control, group 2 being treated with $3 \mathrm{MC}$ alone, group 3 being treated with $3 \mathrm{MC}$ plus simvastatin, and group 4 being treated with simvastatin alone ( $n=12$ in each group). After administration of either PBS (as the control treatment) or simvastatin (1 $\mathrm{mg} / \mathrm{kg}$ ) for 1 day, mice were intravenously (i.v.) injected with either dimethyl sulfoxide or 3MC $(2 \mathrm{mg} / \mathrm{kg})$ for another day. On day 3, mice were i.v. injected with $200 \mu \mathrm{L}$ of $1 \%(\mathrm{w} / \mathrm{v})$ Evan's blue dye, and on day 4, the integrity of the BBB was evaluated with an Evan's Blue dye exclusion test. Mice were sacrificed and transcardially perfused with PBS until the draining fluid became colorless. Brains were then carefully removed and weighed. Following a surface evaluation, the brains were sliced coronally into 1-mm sections and then photographed. Additionally, the whole brains of the mice were cryosectioned $(20 \mu \mathrm{m})$ for immunofluorescence to assess the BBB integrity.

\section{Statistical Analysis}

All values were calculated as the mean $\pm \mathrm{SD}$. One-way analysis of variance or Student's $t$-test were used to assess whether the results differed significantly between the control group and experimental groups. $P$ values less than 0.05 were considered statistically significant.

\section{Results}

\section{MC-Mediated Alteration of RhoA/pPTEN/ pGSK3 $\beta$ in Relation to the Decreased $\beta$-Catenin Level by Phosphorylation}

We previously showed that $3 \mathrm{MC}$-mediated RhoA activation increases protein interactions between RhoA and PTEN, which subsequently leads to PTEN phosphorylation in HUVECs. Colocalization of RhoA with PTEN was verified in 3MC-treated MCVECs in reciprocal co-immunoprecipitations using an anti-RhoA or anti-PTEN antibody at various time periods as shown in Figure 1A. To elucidate $3 \mathrm{MC}$-mediated alterations in RhoA activation, PTEN, GSK3 $\beta$, and $\beta$-catenin phosphorylations and their interwoven relationships, cells were harvested from MCVECs treated with $100 \mathrm{nmol} / \mathrm{L}$ of $3 \mathrm{MC}$ for 2 to 8 hours,
A
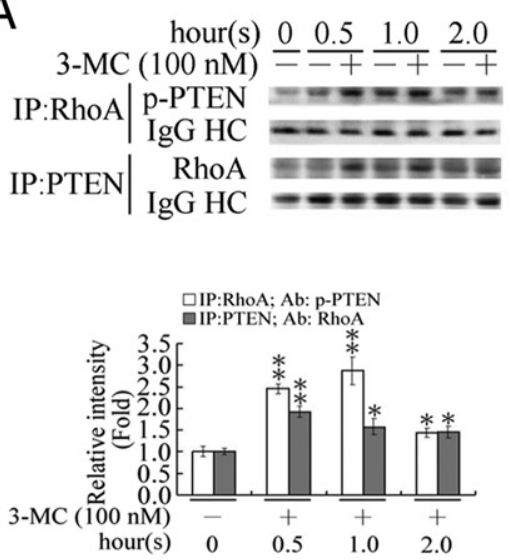

B
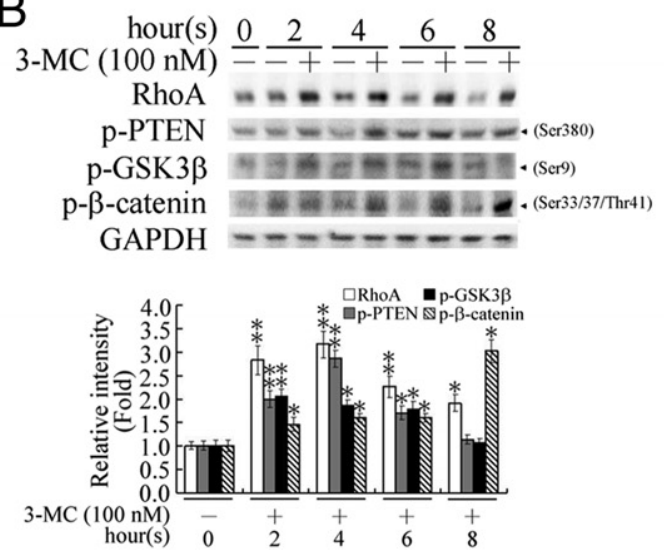
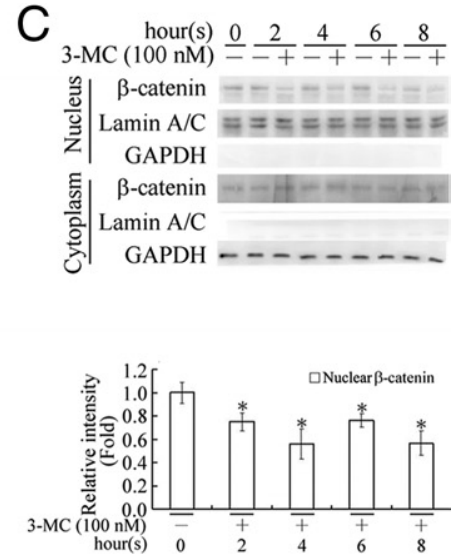

Figure 1. Correlation between $3 \mathrm{MC}$-medated alteration in the pathway of RhoA/PTEN/GSK3 $\beta / \beta$-catenin phosphorylation and decreased levels of $\beta$-catenin in MCVECs. Cells were harvested from MCVECs treated with $100 \mathrm{nmol} / \mathrm{L}$ of $3 \mathrm{MC}$ at the indicated times, and were analyzed by Western blot (A) or were immunoprecipitated by an anti-RhoA or anti-PTEN antibody (Ab) $(2 \mu \mathrm{g})$ and protein A plus G agarose beads ( $20 \mu \mathrm{L})$. Quantitation is shown below. B: The complex was detected with anti-pPTEN or RhoA by Western blot analysis. An IgG heavy chain (IgG HC) was used as an internal control to normalize the Western blot analysis. Quantitation is shown below. C: Cells receiving treatments as indicated were partitioned into nuclear and cytosolic fractions, both of which were probed with anti- $\beta$-catenin. Quantitation is shown to the below. Representative quantitative results of three separate experiments are shown, and data are presented as the mean $\pm \mathrm{SD} .{ }^{*} P<0.05,{ }^{* * *} P<0.01$ versus the control. 
and analyzed by Western blotting. The results, shown in Figure $1 \mathrm{~B}$, indicated that challenging cells with $3 \mathrm{MC}$ significantly increased RhoA expression levels and phosphorylation of PTEN, GSK $3 \beta$, and $\beta$-catenin across the examined time period. Additionally, increased $\beta$-catenin phosphorylation (Figure 1B) was accompanied by a decrease in protein levels of $\beta$-catenin in the nuclear fraction at 2 to 8 hours of 3MC treatment. The correlation between cytosolic fractions became apparent at 6 to 8 hours, but not at 2 to 4 hours, of $3 \mathrm{MC}$ treatment (Figure $1 \mathrm{C}$ ).

\section{Decreased $\beta$-Catenin Levels in Relation to Decreases in Fibronectin and $\alpha 5 \beta 1$ Integrin Expressions and Junction-Cytoskeleton Interactions in 3MC-Treated MCVECs}

We used immunofluorescence staining to further examine 3MC-mediated decreases in the cytosolic-nuclear distribution of $\beta$-catenin. $\beta$-Catenin is a transcription factor coactivator and a key component in the VE-cadherin complex. The results, shown in the upper panel of Figure 2A, indicated that the majority of $\beta$-catenin expression was observed in nuclei, and that cytosolic and nuclear levels of $\beta$-catenin were significantly lower in 3MC-treated MCVECs than in control cells. We then examined the effect of decreased nuclear-cytosolic levels of $\beta$-catenin on the expression of its downstream target genes, and junction-cytoskeleton interactions in MCVECs. Immunofluorescence staining (Figure 2A) and Western blot analysis (Figure 2B) indicated that the decreased $\beta$-catenin level due to $3 \mathrm{MC}$ treatment was concomitant with decreased induction of fibronectin and $\alpha 5 \beta 1$ integrin at various time points. Moreover, the results demonstrated that the 3MC-mediated decrease in cytosolic levels of $\beta$-catenin accompanied decreased junction-cytoskeleton interactions among FAK, VE-cadherin, vinculin, $\beta$-catenin, and $\beta$-actin at 2 to 6 hours of $3 \mathrm{MC}$ treatment, but no effects were observed at 8 hours (Figure $2 \mathrm{C}$ ). These results were obtained by co-IP assay with the anti-VE-cadherin or anti- $\beta$-catenin antibody.

\section{MC-Mediated Inactivation of GSK3 $\beta /$ $\beta$-Catenin via an AhR/RhoA-Dependent Pathway}

We further investigated the roles of AhR/RhoA in 3MC-mediated inactivation of the GSK3 $\beta / \beta$-catenin pathway. Cells were either treated with Y27632, a ROCK inhibitor, or were trans-

A

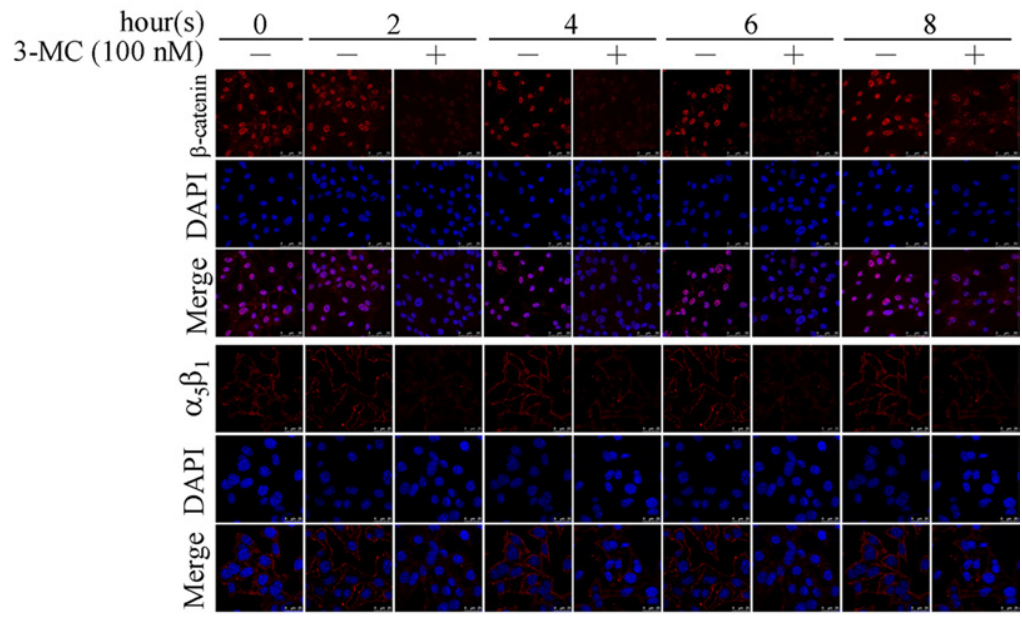

B

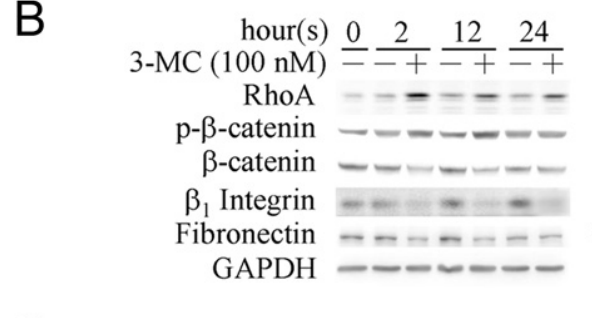

hour(s) $\stackrel{0}{=} \frac{2}{-+} \frac{12}{-+} \frac{24}{-+}$
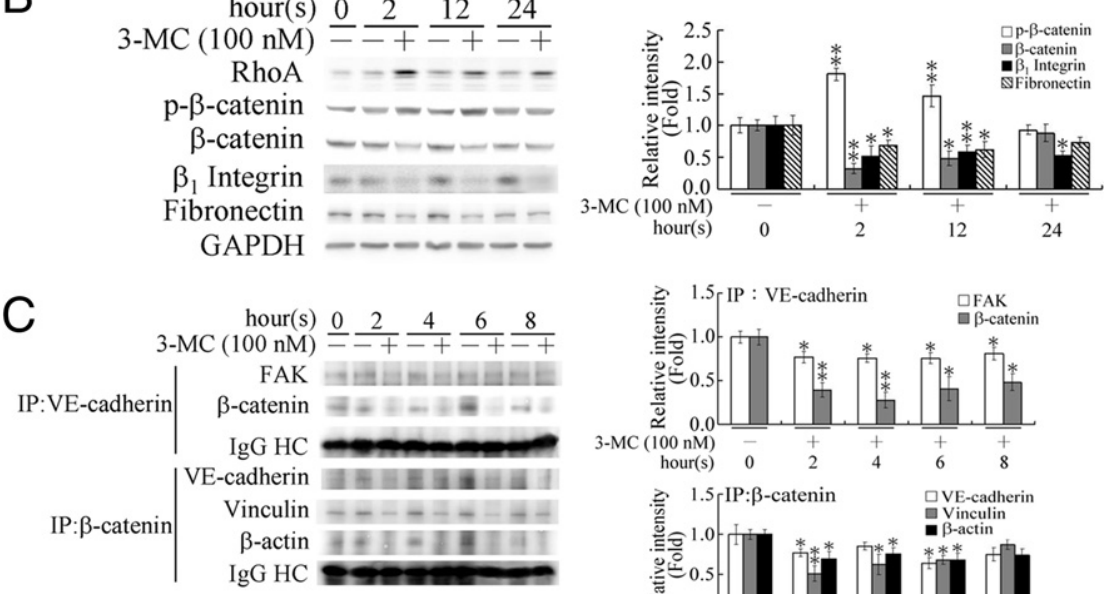

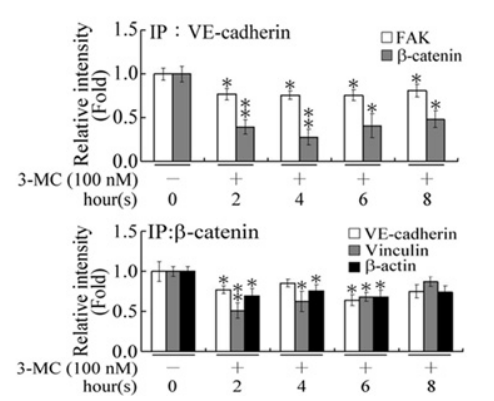

Figure 2. 3MC-mediated decreases in $\alpha 5 \beta 1$ anc fibronectin expression, and interactions among adherens junction proteins in relation to decreased $\beta$-catenin protein levels. A: Cells grown on coverslips challenged with $100 \mathrm{nmol} / \mathrm{L}$ of $3 \mathrm{MC}$ for 0 to 120 minutes were detected using an anti- $\beta$-catenin or an anti- $\alpha 5 \beta 1$ integrin antibody, followed by a Texas Red-conjugated secondary antibody. The cytosolic-nuclear distribution of $\beta$-catenin or expression level of $\alpha 5 \beta 1$ integrin was photographed using a fluorescent confocal microscope, with red spotted patches indicating expression of $\beta$-catenin or $\alpha 5 \beta 1$ integrin. Identical fields were also stained using DAPI to reveal the positions of cell nuclei. Original magnification, $\times 630$. B: Western blot analysis of fibronectin and $\beta 1$ integrin in 3MC-treated MCVECs: at the indicated times, fibronectin and $\beta 1$ integrin were quantitated. GAPDH was used as an internal control for equal loading. C: Cells receiving similar treatments were immunoprecipitated (IP) by an anti-VE-cadherin or anti- $\beta$ catenin antibody. The complex was detected by Western blot with anti-FAK, anti-VE-cadherin, anti-vinculin, and anti- $\beta$-actin antibodies for protein interactions. An IgG heavy chain was used as an internal control for normalization Quantifications on the right show the band intensities of the indicated molecules by densitometry. Data were derived from three independent experiments and are presented as the mean \pm SD. ${ }^{*} P<0.05,{ }^{* * *} P<0.01$ versus the control. 


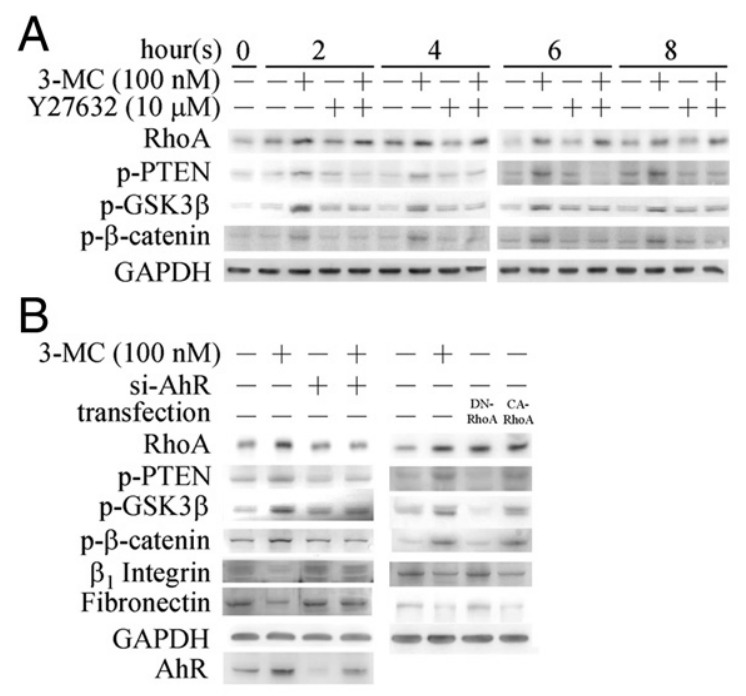

Figure 3. Essential role of RhoA/AhR in the $3 \mathrm{MC}$-mediated increase in $\beta$-catenin phosphorylation through a PTEN/GSK3 $\beta$-dependen mechanism. Cells were either (A) pretreated with Y27632 (a RhoA inhibitor) for 1 hour followed by $3 \mathrm{MC}$ challenge for the indicated time points or (B) transfected with siAhR, DNRhoA, or CARhoA overnight with or without 3MC treatment for 2 hours. Alterations in the levels of $\beta$-catenin, fibronectin, and $\beta 1$ integrin through the proposed signaling pathway were examined GAPDH was used as an internal control to verify equivalent loading. Quantitation is shown to the right. Representative results of three separate experiments are shown, and quantitative data are presented as the mean \pm SD. ${ }^{*} P<0.05,{ }^{* *} P$ $<0.01$, and ${ }^{* * * * *} P<0.001$ versus the control; ${ }^{\dagger} P<$ $0.05,{ }^{\ddagger} P<0.01$ versus $3 \mathrm{MC}$ alone. fected with small interference (si)AhR, dominant negative (DN) RhoA (T19N), or constitutive (CA)RhoA (Q63L). The results, shown in Figure 3A, demonstrated that Y27632 reversed the phosphorylation of PTEN/GSK3 $\beta / \beta$-catenin induced by $3 \mathrm{MC}$. The requirement for AhR/RhoA signaling in 3MC-mediated inactivation of GSK3 $\beta / \beta$-catenin was further substantiated by loss- and gain-of-function approaches (ie, CARhoA, DNRhoA, and siAhR). The results (Figure $3 \mathrm{~B}$ ) demonstrated that knockdown of the AhR by siAhR reversed the 3MC-mediated decreases in fibronectin and $\beta 1$ integrin by alleviating PTEN/ GSK3 $\beta / \beta$-catenin phosphorylation. Moreover, the results showed that DNRhoA overexpression caused $3 \mathrm{MC}$ to exert the opposite effect of increasing fibronectin and $\beta 1$ integrin levels, but CARhoA mimicked the effect of 3MC. These findings suggest the essential role of RhoA activation in this event.

\section{Activation of PKC $\delta$, But Not AKT, Is Involved in Inactivation of $G S K 3 \beta / \beta$-Catenin in 3MC-Mediated Down-Regulation of Fibronectin and $\alpha 5 \beta 1$ Integrin}

As shown in Figure 1, we demonstrated increased PTEN phosphorylation by 3MC-mediated AhR/RhoA activation. Additionally, PTEN was shown to increase levels of phosphatidylinositol 4,5-bisphosphate (PIP2) and thereafter diacylglycerol, which activate the protein kinase $\mathrm{C}$ (PKC) pathway. ${ }^{31}$ To investigate whether PKC is a downstream target of PTEN in 3MC-treated MCVECs, cell lysates were partitioned into cytosolic and membrane fractions. As shown in Figure 4A, the activated form of PKC $\delta$ in membrane fractions increased with $3 \mathrm{MC}$ treatment. Similarly, CARhoA overexpression increased the activated form of PKC $\delta$ in membranes, whereas DNRhoA overexpression caused the opposite effect, suggesting that RhoA activation is essential for $\mathrm{PKC} \delta$ activation. Because PI3K and AKT were also shown to initiate phosphorylation of GSK3 $\beta / \beta$-catenin, their involvement in the effect of $3 \mathrm{MC}$ was examined using wortmannin and YS-49, which are, respectively, a PI3K inhibitor and activator. The results
(Figure 4B) showed that although wortmannin decreased AKT phosphorylation, it mimicked the effect of $3 \mathrm{MC}$ in increasing the phosphorylation of GSK3 $\beta / \beta$-catenin. By contrast, YS-49 increased AKT phosphorylation but decreased phosphorylation of GSK3 $\beta / \beta$-catenin by $3 \mathrm{MC}$. These findings suggested that $3 \mathrm{MC}$ might inhibit PI3K activation, and that PI3K/AKT activation is not directly involved in the 3MC-mediated increased phosphorylation of GSK3 $\beta / \beta$-catenin.

We also investigated the causal role of $F A K / R h o A /$ $\mathrm{PKC} \delta / \beta$-catenin in 3MC-mediated down-regulation of $\mathrm{fi}-$ bronectin and $\alpha 5 \beta 1$ integrin. Cells were pretreated with various inhibitors of these signaling molecules, and the results were analyzed by Western blot and RT-PCR analysis. As shown in Figure $4 \mathrm{C}$, the inactivation of RhoA and PKC $\delta$ by $Y 27632$ and rottlerin, respectively, and the inhibition of proteasomal degradation of FAK and $\beta$-catenin by $\mathrm{Mg} 132$, all reversed 3MC-mediated down-regulation of fibronectin and $\alpha 5 \beta 1$ integrin. These findings suggested the importance of FAK/RhoA/PKC $\delta / \beta$-catenin in the transcriptional regulation of fibronectin and $\alpha 5 \beta 1$ integrin by $3 \mathrm{MC}$.

\section{Decreased Binding Activities of $\beta$-Catenin to the TCF/LEF1 Response Elements in the Promoters of Fibronectin and $\alpha 5 \beta 1$ Induced by $3 M C$}

To determine whether the 3MC-induced decrease in $\beta$-catenin level decreased the binding activity of $\beta$-catenin to its target genes containing TCF/LEF1-binding sites, we performed electrophoretic mobility shift and ChIP assays. Importantly, based on the in silico analysis using MatInspector Professor software, putative TCF/ LEF $1 / \beta$-catenin binding sites in fibronectin/ $\alpha 5 \beta 1$ integrin promoters were identified at positions -160 to $-136 \mathrm{bp}$ for fibronectin, at -455 to -431 bp for $\alpha 5$, and at -455 to $-431 \mathrm{bp}$ for $\beta 1$. The results (Figure $5 \mathrm{~A}$ ) using putative TCF/LEF $1 / \beta$-catenin binding sites derived from fibronectin/ $\alpha 5 \beta 1$ integrin promoters showed that $3 \mathrm{MC}$ decreased 
A
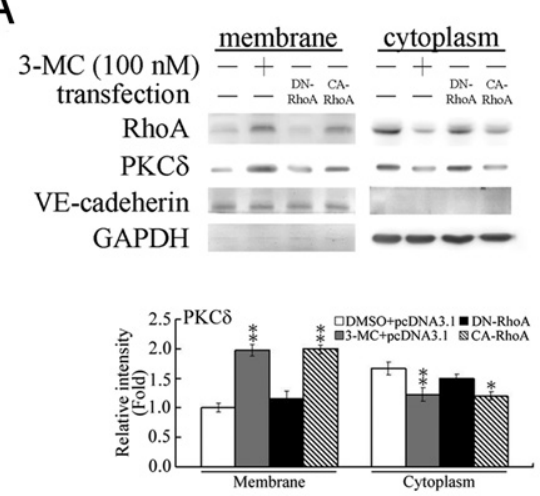

B

3-MC $(100 \mathrm{nM})-+++-$

Wortmannin $(10 \mu \mathrm{M})--+-+$

YS-49 $(2 \mu \mathrm{M})---++$

RhoA - - - -

$\mathrm{p}$-Akt $-\mathrm{PKC}-\ldots$

PKC $=-\cdots-\cdots$

$\mathrm{p}-\mathrm{GSK} 3 \beta-2--$

p- $\beta$-catenin -----

GAPDH $-\cdots-\cdots$

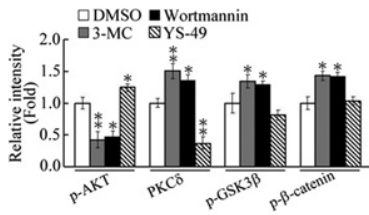

C

3-MC $(100 \mathrm{nM})-++++---$ Rottlerin $(1 \mu \mathrm{M})--+--+--$ Y27632 $(10 \mu \mathrm{M})---+--+-$ $\operatorname{Mg} 132(5 \mu \mathrm{M})---++-+$
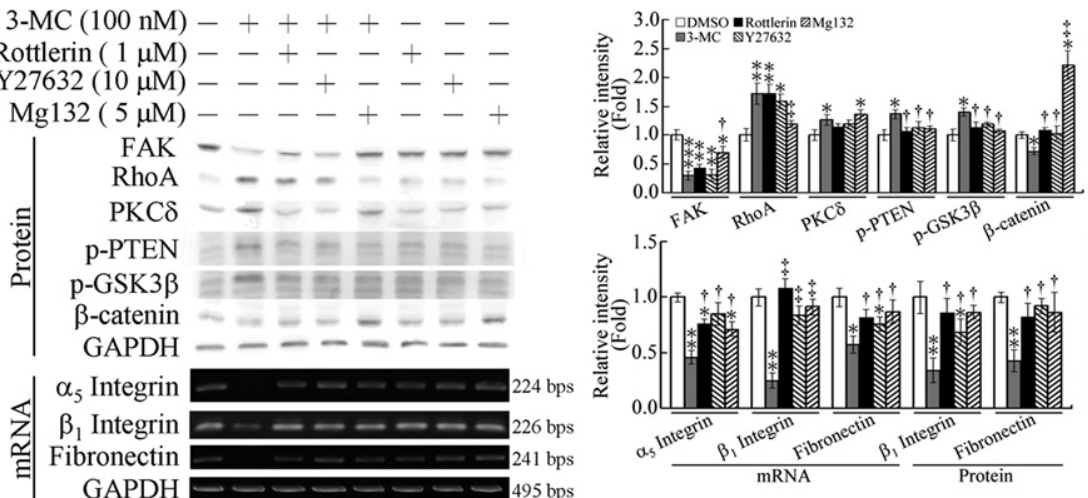

Figure 4. Importance of protein kinase $\mathrm{C} \delta$ (PKC $\delta$ ), but not AKT, in 3MC-mediated downregulation of fibronectin and $\alpha 5 \beta 1$ integrin through a GSK3 $\beta / \beta$-catenin-dependent pathway. A: Cells were treated with $3 \mathrm{MC}$ for 2 hours or transfected with pcDNA-CARhoA (Q63L) or pcDNA-DNRhoA (T19N) overnight as described in Materials and Methods. Cell lysates were partitioned into cytosolic and membrane fractions, and expression levels of RhoA and PKC $\delta$ were assessed by a Western blot analysis with GAPDH and VE-cadherin as internal controls for each fraction, respectively. Quantitation was also performed (below). B: Cells were pretreated with YS-49 or wortmannin for 1 hour followed by 2 hours of treatment with $100 \mathrm{nmol} / \mathrm{L} 3 \mathrm{MC}$. The resulting cell lysates were analyzed by Western blotting for levels of pAKT or RhoA/PKC $\delta /$ pGSK $3 \beta / \mathrm{p}-\beta$-catenin. Quantitation is shown below. C: MCVECs were pretreated with Y27632 (a ROCK inhibitor), rottlerin (a PKC $\delta$ inhibitor), or Mg132 (a S26 proteasome inhibitor) for 1 hour, before 3MC challenge for another 2 hours. Samples were analyzed by Western blotting (protein) and RT-PCR (mRNA) for the components of the proposed pathway and endpoints of $\mathrm{fi}_{-}$ bronectin and $\alpha 5 \beta 1$ integrin using GAPDH as an internal control. Quantitation is shown to the right. Representative quantitative results of four separate experiments are shown, and data are presented as the mean $\pm \mathrm{SD} .{ }^{*} P<0.05,{ }^{* *} P<$ 0.01 , and ${ }^{* * * * *} P<0.001$ versus the control; ${ }^{\dagger} P<$ $0.05,{ }^{\ddagger} P<0.01$ versus $3 \mathrm{MC}$ alone. the DNA-binding activities of $\beta$-catenin to TCF/LEF $1 / \beta$ catenin binding sites. Binding activities were abolished by their respective mutants and competition of a 100-fold molar excess of unlabeled oligonucleotides relative to the biotin-labeled probe. Furthermore, the effects of 3MC on the association of $\beta$-catenin to TCF/LEF1/ $\beta$-catenin binding sites in fibronectin $/ \alpha 5 / \beta 1$ promoters were examined by a ChIP assay in cells after various treat-
A

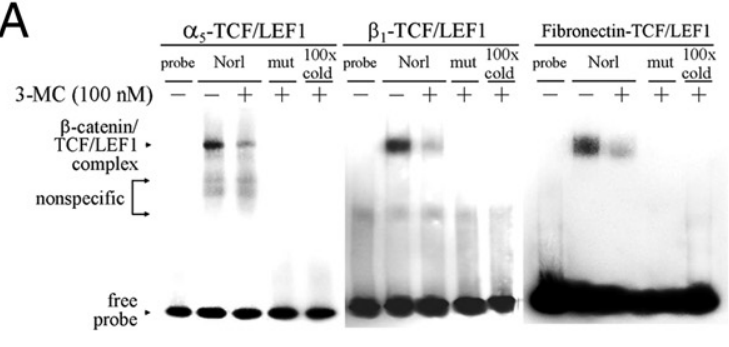

B
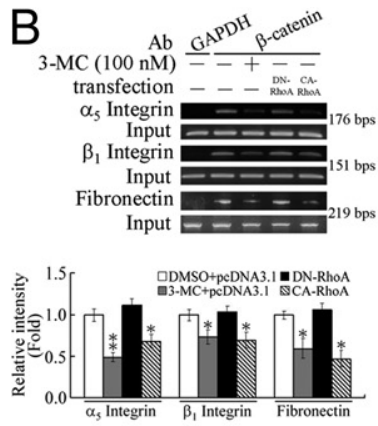
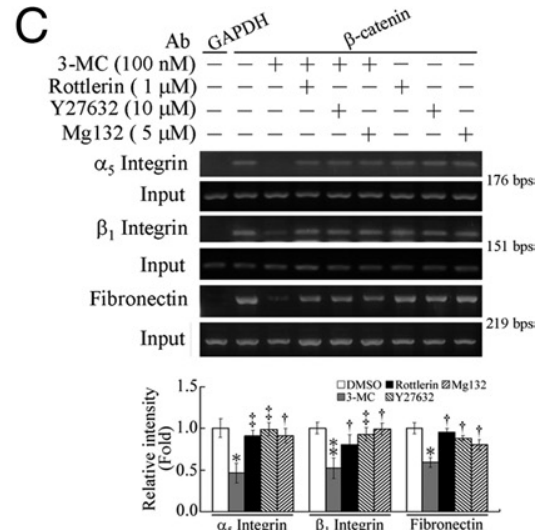

Figure 5. 3MC-mediated decreases in $\beta$-catenin binding activities to TCF/LEF1 binding sites of fibronectin/ $\alpha 5 \beta 1$ integrin promoters through a RhoA/PKC $\delta /$ proteasome-dependent pathway. A: An electrophoretic mobility shift assay was performed as described in Materials and Methods. A ChIP assay was performed in cells overexpressing DNRhoA, or CARhoA overnight (B), and in cells pretreated with various inhibitors (as in Figure 4C) followed by $3 \mathrm{MC}$ challenge for 1 hour (C). The DNA associated with $\beta$-catenin-TCF/LEF1 was immunoprecipitated with an anti- $\beta$-catenin antibody, and PCR amplification was used to determine the extent of $\beta$-catenin association with the functional $\beta$-catenin-TCF/LEF1 binding sites in fibronectin and $\alpha 5 \beta 1$ integrin promoters. An anti-GAPDH antibody was used as a negative control for the ChIP assays. B and C: Quantitation is shown below. Representative quantitative results of three separate experiments are shown, and data are presented as the mean $\pm \mathrm{SD} .{ }^{*} P<0.05,{ }^{* * *} P<0.01$ versus the control; ${ }^{\dagger} P<0.05,{ }^{\ddagger} P<0.01$ versus $3 \mathrm{MC}$ alone 
ments (Figure 5, B and C). We caused the 3MC-induced association of $\beta$-catenin with the TCF/LEF1/ $\beta$-catenin binding sites by pulling down the target fragments in the promoters of fibronectin $/ \alpha 5 \beta 1$ integrin using an anti- $\beta$ catenin antibody. We used PCR to amplify the immunoprecipitated TCF/LEF $1 / \beta$-catenin binding site fragments, and examined the associations using primers derived from fibronectin $/ \alpha 5 \beta 1$ promoters. The ChIP assays (Figure 5B) showed that CARhoA overexpression mimicked the effect of $3 \mathrm{MC}$ in significantly decreasing the level of enrichment of the promoters of fibronectin and $\alpha 5 \beta 1$ integrin, whereas DNRhoA overexpression caused the opposite effect. The results implied that RhoA activation is involved in the decreased $\beta$-catenin-TCF/LEF1 transactivation of fibronectin and $\alpha 5 \beta 1$ integrin genes induced by $3 \mathrm{MC}$. Furthermore, the results shown in Figure $5 \mathrm{C}$ demonstrated that $3 \mathrm{MC}$-mediated effects could be reversed by pretreatment with rottlerin, Y27632, and Mg132, a finding that indicated the dependency of RhoA and PKC $\delta$ activation and $F A K / \beta$-catenin down-regulation in $\beta$-catenin transactivational activity.

\section{Simvastatin and Pravastatin Rescue the 3MC-Mediated Down-Regulation of Fibronectin/ $\alpha 5 \beta 1$ and Instability of Adherens Junctions by Inhibiting RhoA Activation}

According to the above findings, 3MC-mediated RhoA activation is essential in MCVECs for inhibiting fibronectin and $\alpha 5 \beta 1$ integrin expressions, and for junction-cytoskeleton interactions. We used Western blot and RT-PCR analyses to examine whether simvastatin and pravastatin, inhibitors of RhoA activation, would prevent 3MCmediated alteration of MCVECs. The results (Figure 6A) showed that simvastatin and pravastatin significantly decreased the activated forms of RhoA/PKC $\delta$ in membrane fractions. Subsequently, the drugs effectively prevented $3 \mathrm{MC}$-mediated decreases in fibronectin and $\alpha 5 \beta 1$ integrin induction by eliminating phosphorylation of PTEN, GSK $3 \beta$, and $\beta$-catenin (Figure $6 \mathrm{~B}$ ). Furthermore, the co-IP assay using an anti-VE-cadherin antibody (Figure $6 \mathrm{C})$ demonstrated that $3 \mathrm{MC}$ decreased adherens junction associations among FAK, vinculin, $\beta$-catenin, and $\beta$-actin, but that this effect was reversed by the additional treatment of simvastatin and pravastatin.

\section{Therapeutic Effect of Simvastatin in Preventing 3MC-Mediated Disruption of Brain Vascular Integrity}

Given the lipophilic property of simvastatin and its in vitro effects, simvastatin was further used as a therapeutic approach to alleviate 3MC-mediated alteration of the BBB integrity. The images in Figure 7A were selected from four separate experiments showing the brains of mice in each group (control, $3 \mathrm{MC}$, combined $3 \mathrm{MC}$ and simvastatin, and simvastatin). Marked leakage of Evan's Blue dye in 3MC-treated mice brains indicated compromised BBB integrity, compared with the control. Mice
A

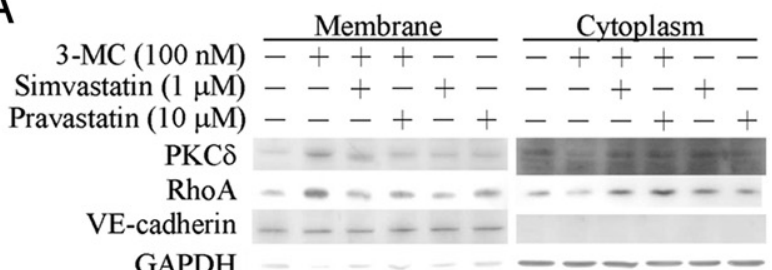

GAPDH

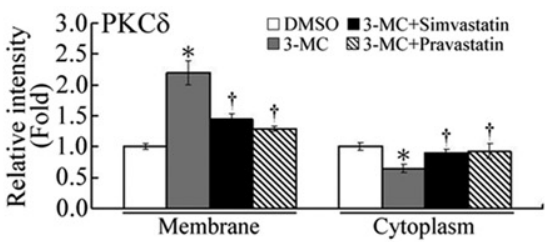

$\mathrm{B}$
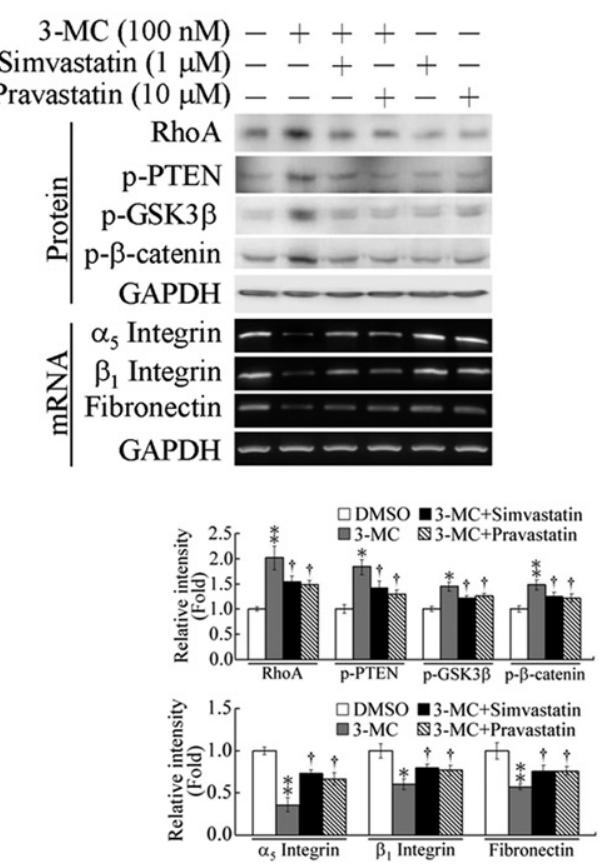

C

3-MC $(100 \mathrm{nM})-+++--$

Simvastatin $(1 \mu \mathrm{M})--+-+$

Pravastatin $(10 \mu \mathrm{M})---+-+$

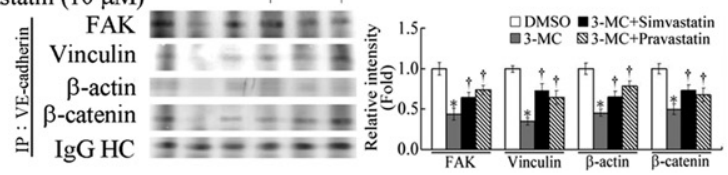

Figure 6. Abolition of $3 \mathrm{MC}$-mediated inhibition of fibronectin $/ \alpha 5 \beta 1$ integrin expression and adherens junction protein interactions by simvastatin/pravastatin-mediated RhoA inactivation. A: Cells were pretreated with simvastatin or pravastatin for 1 hour followed by 2 hours of treatment with $100 \mathrm{nmol} / \mathrm{L} 3 \mathrm{MC}$. Effects of statins in the increased activated forms of RhoA and PKC $\delta$ in membrane fractions by $3 \mathrm{MC}$ were analyzed by Western blots. Quantitation is shown below. B: The effects of statin derivatives on 3MC-mediated down-regulation of fibronectin and $\alpha 5 \beta 1$ integrin by the proposed signaling pathway were analyzed by Western blotting and RT-PCR. Quantitation is shown to the right. C: Cells with similar treatments were co-immunoprecipitated with an anti-vinculin antibody followed by a Western blot analysis of junction-cytoskeleton-associated proteins. Quantitation is shown to the right. Representative results of three separate experiments are shown, and data are presented as the mean $\pm \mathrm{SD} .{ }^{*} P<0.05$ ${ }^{* *} P<0.01$ versus the control; ${ }^{\dagger} P<0.05$ versus $3 \mathrm{MC}$ alone.

pretreated with simvastatin and then treated with $3 \mathrm{MC}$ showed less leakage of Evan's Blue dye in the brain, which inferred restoration of the BBB integrity. The leaked Evan's Blue dye induced by $3 \mathrm{MC}$ was found to be de- 
A
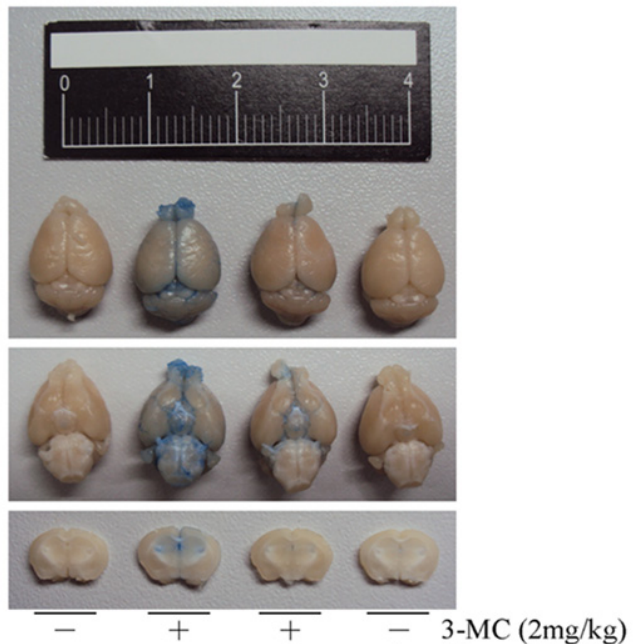

$\begin{array}{lllll}- & + & + & - & 3-\mathrm{MC}(2 \mathrm{mg} / \mathrm{kg}) \\ - & - & + & + & \text { Simvastatin }(1 \mathrm{mg} / \mathrm{kg})\end{array}$

B

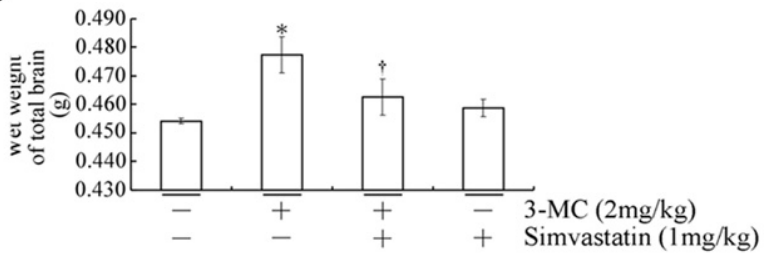

C

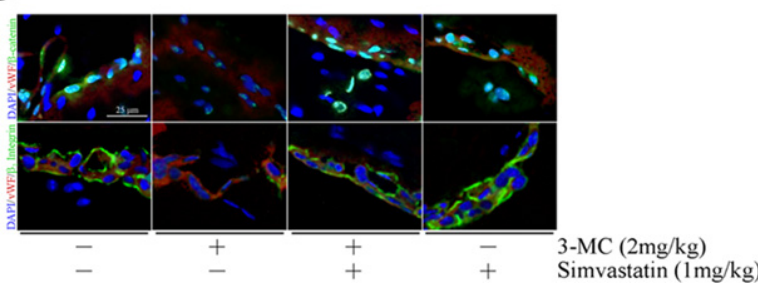

Figure 7. Therapeutic intervention with simvastatin to maintain brain vascular integrity in mice challenged with 3MC. A: Representative results of whole brains (dorsal and ventral views in upper and middle panels) and brain coronal sections ( $1 \mathrm{~mm}$, lower panel) with the indicated treatments from four separate experiments are shown. B: Mean weights of mice brains from four different groups ( $n=12$ in each group). Results are shown as mean $\pm \mathrm{SD} .{ }^{*} P<0.05$ versus the control; ${ }^{\dagger} P<0.05$ versus $3 \mathrm{MC}$. C: Examination of the expressions of $\beta$-catenin and $\beta 1$ integrin in murine brain tissues by immunohistostaining. Tissue sections $(20 \mu \mathrm{m})$ were detected by an anti$\beta$-catenin (green, upper panel) or anti- $\beta 1$ integrin (green, lower panel) antibody; endothelial cells were identified by positive immunostaining of von Willebrand factor protein (vWF; red). Identical fields were stained using DAPI (blue) to reveal the positions of cell nuclei. Merged images are also shown. Original magnification, $\times 630$.

posited in brain tissues (Figure 7A). The brains of 3MCtreated mice were larger than those of the control group or mice that received simvastatin intervention; this result may have been due to edema as a result of disruption of the vascular barrier. Furthermore, the brain weights of mice challenged with $3 \mathrm{MC}$ were significantly increased relative to those of control mice, by approximately $5.2 \%$. This phenomenon was markedly attenuated with additional simvastatin treatment, with up to $75 \%$ reduction, demonstrating the protective effects of simvastatin against 3MC-mediated disruption in the BBB integrity (Figure 7B). We used histo-immunofluorescence staining with anti- $\beta$-catenin and anti- $\beta 1$ integrin antibodies to in- vestigate whether the decrease in $\beta$-catenin induced by $3 \mathrm{MC}$ in integrin down-regulation contributed to these effects. Brain slices were also stained with vWF for endothelial cells and DAPI for cell nuclei. The results, shown in Figure $7 \mathrm{C}$, demonstrated that expressions of $\beta$-catenin (upper panel) and $\beta 1$ integrin (lower panel) in brain vessels of mice challenged with $3 \mathrm{MC}$ indeed appeared to be downregulated compared to those of control animals. Once again, the effect was significantly reversed by additional simvastatin pretreatment. These findings suggested that a reduction in $\beta$-catenin and $\beta 1$ integrin was associated with 3MC-mediated disruption of the BBB integrity.

\section{Discussion}

Previous research has indicated that the presence and functional activity of AhR in isolated murine cerebral vascular endothelial cells and astrocytes could be targets of toxicity in the vascular endothelium of the central nervous system. ${ }^{2}$ The present study used a mouse cerebral endothelial cell system to examine the molecular mechanisms of an AhR agonist, 3MC, in altering the BBB integrity and its dependence on the AhR/RhoA. We demonstrated that $3 \mathrm{MC}$ increased $\beta$-catenin down-regulation by phosphorylation through a mechanism dependent on AhR, RhoA, pPTEN, PKC $\delta$, and pGSK3 $\beta$. The increased $\beta$-catenin down-regulation induced by $3 \mathrm{MC}$ not only affected the stability of junction-cytoskeleton interactions, but also decreased expressions of fibronectin and $\alpha 5 \beta 1$ integrin, which are essential molecules in cell-matrix interactions (Figure 8). We also identified

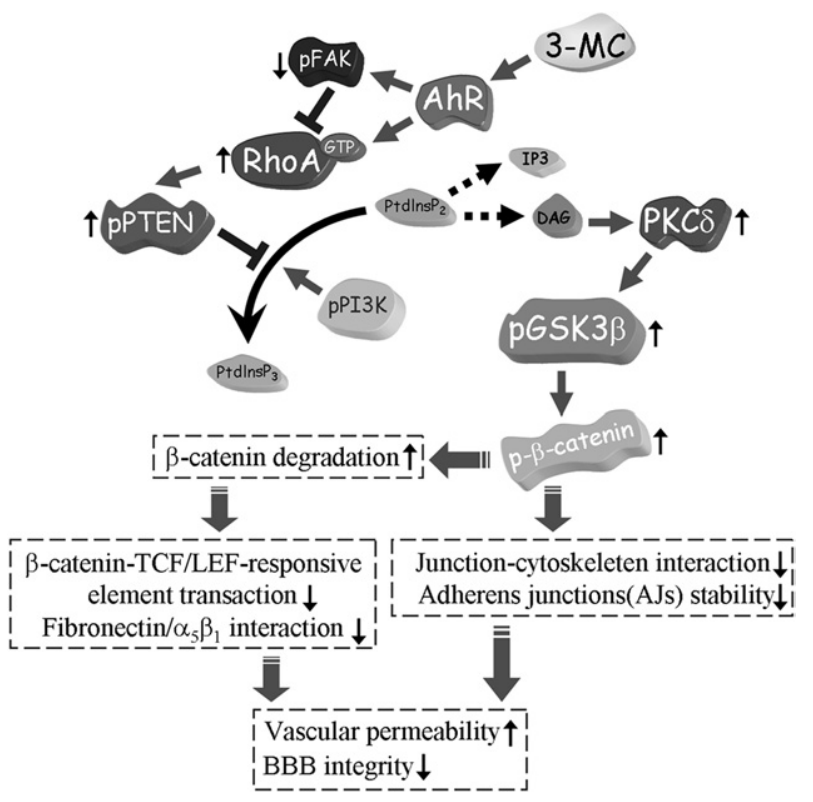

Figure 8. Summary of the signal pathways in the inhibition of fibronectin and $\alpha 5 \beta 1$ integrin expression and junction-cytoskeleton interactions as a result of $\beta$-catenin down-regulation by $3 \mathrm{MC}$. AhR/RhoA activation by $3 \mathrm{MC}$ initiated the phosphorylation of PTEN, PKC $\delta$, and GSK $3 \beta$, leading to $\beta$-catenin down-regulation by phosphorylation. The in vitro finding was verified by an in vivo functional assessment of the blood-brain boundary integrity in mice challenged with $3 \mathrm{MC}$. The signal pathways identified in this study are shown as solid lines with arrows, and proposed correlations are indicated by dashed lines with arrows. 
functional TCF/LEF1 binding sites located on the promoters of fibronectin and $\alpha 5 \beta 1$ integrin that were downregulated by the $3 \mathrm{MC}$-mediated decrease in $\beta$-catenin transactivational activity. Our in vitro findings were confirmed in vivo by showing the increased permeability of the BBB in 3MC-treated mice, indicative of the detrimental effect of $3 M C$ on brain integrity. Simvastatin, a RhoA inhibitor, was shown to provide a therapeutic approach to prevent murine BBB disruption by $3 \mathrm{MC}$.

We demonstrate for the first time that AhR/RhoA activation by an AhR agonist, 3MC, decreases the expression of fibronectin and $\alpha 5 \beta 1$ integrin, which in turn disrupts brain vascular integrity. Evidence of the proposed signal pathway for 3MC-mediated alteration in endothelial integrity was provided by its respective inactivator(s), including siAhR, RhoA inhibitors (ie, Y27632, DNRhoA, simvastatin, and pravastatin), rottlerin (a PKC $\delta$ inhibitor), and Mg132 (a proteasome inhibitor). These inhibitors prevented 3MC-mediated down-regulation of fibronectin and $\alpha 5 \beta 1$ integrin. By contrast, CARhoA, a constitutively active RhoA, mimicked the effect of $3 M C$ in activating PTEN/PKC $\delta /$ PGSK3 $\beta$, thus contributing to the decreased $\beta$-catenin levels. Notably, Mg132 not only counteracted 3MC-mediated decreases in levels of FAK and $\beta$-catenin, but also decreased levels of RhoA and pGSK3 $\beta$ (Figure $4 C$ ). This finding was congruent with our previous observation in HUVECs that when FAK was subjected to proteasomal degradation, it negatively regulated the level and activity of RhoA. ${ }^{13}$ The current study further demonstrated in vivo that simvastatin prevented 3MC-mediated disruption of the brain's vascular integrity by inhibiting RhoA activation.

In most cases, PI3K and its downstream PKB/AKT are responsible for GSK3 phosphorylation. However, the PKC family has been shown to play a key role in GSK3 phosphorylation in hemopoietic cell types in response to various cytokine treatments. ${ }^{32}$ Our results demonstrated that $\mathrm{PKC} \delta$, an isoform of the PKC family, was essential for GSK $3 \beta$ phosphorylation, as indicated by the inhibition of the response by a PKC inhibitor. By contrast, YS-49, a PI3K activator, reversed 3MC-mediated phosphorylation of GSK3 $\beta$ but increased AKT phosphorylation. Conversely, wortmannin, a PI3K inhibitor, inactivated AKT but resembled the effect of $3 M C$ in inactivating GSK3 $\beta$ by phosphorylation. We surmised that PI3K inactivation induced by $3 \mathrm{MC}$, together with RhoA-mediated PTEN phosphorylation (Figure 1A), might lead to $\mathrm{PKC} \delta$ activation through increased conversion of PIP2 to diacylglycerol by phosphoinositide-specific phospholipase C. The details of this proposed mechanism require further investigation.

The current study also investigated an area of increasing interest, namely the effect of interactions between focal adhesions and the extracellular matrix in cellular behavior. Previous research found that fibronectin-depleted cells apparently decreased paxillin and phosphotyrosine staining at sites of cell-cell adhesion, which further decreased the activities of Rac1 and RhoA. They are essential for lamellipodia and prominent stress fiber formation, thus causing a spreading defect. ${ }^{7}$ However, our results indicated that RhoA activation by $3 \mathrm{MC}$ decreased $\beta$-catenin levels by phosphorylation through a pPTEN/ $\mathrm{PKC} \delta /$ pGSK3 $\beta$-dependent pathway. This process led to disruption of brain vascular integrity by down-regulating fibronectin $/ \alpha 5 \beta 1$ integrin expression and destabilizing junction-cytoskeleton interactions. Interestingly, our in vivo findings demonstrated that 3MC-treated mice exhibited substantially increased Evan's Blue accumulation in brain regions containing the BBB, accompanied by increased brain sizes and weights. This suggests the occurrence of brain edema as a result of a breakdown in BBB integrity. Similarly, another recent study showed that atheroprone shear stress served as a potent activator of endothelial $\beta$-catenin/TCF/LEF1 signaling through a PECAM-1/GSK3 $\beta$-dependent mechanism, which in turn drove the transcription of fibronectin in regions predisposed to atherosclerosis. ${ }^{33}$ The same study found that fibronectin up-regulation was prone to the progression of atherosclerosis; our own findings suggested that the down-regulation of fibronectin and integrin may disrupt the BBB integrity.

The current study first demonstrated that $3 \mathrm{MC}$ decreased $\beta$-catenin protein levels by a RhoA/pPTEN/ PKC $\delta /$ pGSK3 $\beta$-dependent degradation pathway. Decreased $\beta$-catenin protein levels led to decreased interactions among the adherens junction-associated proteins, including FAK, VE-cadherin, vinculin, and $\beta$-actin. Additionally, the decreased $\beta$-catenin transactivational activity resulted in decreased transcriptional regulation of $\alpha 5 \beta 1$ integrin and fibronectin in 3MC-challenged MCVECs. Our research also demonstrated that therapeutic intervention with simvastatin and pravastatin, which are RhoA inhibitors, could prevent 3MC-mediated alterations in MCVECs. The mechanism of action was recovery of the level of $\beta$-catenin, suggesting the pivotal role of Rho $A$ in this event. Our findings provide new insights into the role of RhoA in $3 \mathrm{MC}$-mediated alteration of BBB integrity. Our results may also facilitate the identification of novel therapeutic targets for statin derivatives as RhoA inhibitors for maintaining endothelial vascular integrity in AhR-mediated endothelial injury.

\section{Acknowledgments}

We acknowledge Dr. Jan Xu for technical support in preparing MCVECs.

\section{References}

1. Yuan SY: Protein kinase signaling in the modulation of microvascular permeability. Vasc Pharmacol 2002, 39:213-223

2. Filbrandt CR, Wu Z, Zlokovic B, Opanashuk L, Gasiewicz TA: Presence and functional activity of the aryl hydrocarbon receptor in isolated murine cerebral vascular endothelial cells and astrocytes. Neurotoxicology 2004, 25:605-616

3. Geiger B, Bershadsky A, Pankov R, Yamada KM: Transmembrane crosstalk between the extracellular matrix-cytoskeleton crosstalk. Nat Rev Mol Cell Biol 2001, 2:793-805

4. Luscinskas FW, Lawler J: Integrins as dynamic regulators of vascular function. FASEB J 1994, 8:929-938

5. Schaller MD: Biochemical signals and biological responses elicited by the focal adhesion kinase. Biochim Biophys Acta 2001, 1540:1-21 
6. van Nieuw Amerongen GP, van Delft S, Vermeer MA, Collard JG, van Hinsbergh VW: Activation of RhoA by thrombin in endothelial hyperpermeability: role of Rho kinase and protein tyrosine kinases. Circ Res 2000, 87:335-340

7. Cseh B, Fernandez-Sauze S, Grall D, Schaub S, Doma E, Van Obberghen-Schilling $\mathrm{E}$ : Autocrine fibronectin directs matrix assembly and crosstalk between cell-matrix and cell-cell adhesion in vascular endothelial cells. J Cell Sci 2010, 123:3989-3999

8. Nobes CD, Hall A: Rho GTPases control polarity, protrusion, and adhesion during cell movement. J Cell Biol 1999, 144:1235-1244

9. Yamaguchi R, Mazaki Y, Hirota K, Hashimoto S, Sabe H: Mitosis specific serine phosphorylation and downregulation of one of the focal adhesion protein, paxillin. Oncogene 1997, 15:1753-1761

10. Kawada M, Amemiya M, Ishizuka M, Takeuchi T: Cytostatin, an inhibitor of cell adhesion to extracellular matrix, selectively inhibits protein phosphatase 2A. Biochim Biophys Acta 1999, 1452:209-217

11. Gomez J, Martinez AC, Gonzalez A, Rebollo A: Dual role of Ras and Rho proteins: at the cutting edge of life and death. Immunol Cell Biol 1998, 76:125-134

12. Riento K, Ridley AJ: Rocks: multifunctional kinases in cell behaviour. Nat Rev Mol Cell Biol 2003, 4:446-456

13. Chang CC, Tsai SY, Lin H, Li HF, Lee YH, Chou Y, Jen CY, Juan SH: Aryl-hydrocarbon receptor-dependent alteration of FAK/RhoA in the inhibition of HUVEC motility by 3-methylcholanthrene. Cell Mol Life Sci 2009, 66:3193-3205

14. Totsukawa G, Yamakita Y, Yamashiro S, Hartshorne DJ, Sasaki Y, Matsumura F: Distinct roles of ROCK (Rho-kinase) and MLCK in spatial regulation of MLC phosphorylation for assembly of stress fibers and focal adhesions in 3T3 fibroblasts. J Cell Biol 2000, 150: 797-806

15. Bazzoni G, Dejana E: Pores in the sieve and channels in the wall: control of paracellular permeability by junctional proteins in endothelial cells. Microcirculation 2001, 8:143-152

16. Dejana E, Bazzoni G, Lampugnani MG: Vascular endothelial (VE)cadherin: only an intercellular glue? Exp Cell Res 1999, 252:13-19

17. Wong RK, Baldwin AL, Heimark RL: Cadherin-5 redistribution at sites of TNF-alpha and IFN-gamma-induced permeability in mesenteric venules. Am J Physiol 1999, 276:H736-H748

18. Del Maschio A, Zanetti A, Corada M, Rival Y, Ruco L, Lampugnan MG, Dejana E: Polymorphonuclear leukocyte adhesion triggers the disorganization of endothelial cell-to-cell adherens junctions. J Cell Biol 1996, 135:497-510

19. Gumbiner BM: Signal transduction of beta-catenin. Curr Opin Cell Biol 1995, 7:634-640

20. Hinck L, Nathke IS, Papkoff J, Nelson WJ: Beta-catenin: a common target for the regulation of cell adhesion by Wnt-1 and Src signaling pathways. Trends Biochem Sci 1994, 19:538-542
21. He TC, Sparks AB, Rago C, Hermeking $H$, Zawel L, da Costa LT, Morin PJ, Vogelstein B, Kinzler KW: Identification of c-MYC as a target of the APC pathway. Science (New York, NY) 1998, 281:1509-1512

22. He TC, Chan TA, Vogelstein B, Kinzler KW: PPARdelta is an APCregulated target of nonsteroidal anti-inflammatory drugs. Cell 1999, 99:335-345

23. Tetsu O, McCormick F: Beta-catenin regulates expression of cyclin D1 in colon carcinoma cells. Nature 1999, 398:422-426

24. Chan KC, Wu CH, Huang CN, Lan KP, Chang WC, Wang CJ: Simvastatin inhibits glucose-stimulated vascular smooth muscle cell migration involving increased expression of RhoB and a block of Ras/ Akt signal. Cardiovasc Ther 2012, 30:75-84

25. Ohkawara H, Ishibashi T, Saitoh S, Inoue N, Sugimoto K, Kamioka M, Uekita H, Kaneshiro T, Ando K, Takuwa Y, Maruyama Y, Takeishi Y: Preventive effects of pravastatin on thrombin-triggered vascular responses via Akt/eNOS and RhoA/Rac1 pathways in vivo. Cardiovasc Res 2010, 88:492-501

26. Pang $\mathrm{PH}$, Lin $\mathrm{YH}$, Lee $\mathrm{YH}$, Hou HH, Hsu SP, Juan SH: Molecular mechanisms of p21 and p27 induction by 3-methylcholanthrene, an aryl-hydrocarbon receptor agonist, involved in antiproliferation of human umbilical vascular endothelial cells. J Cell Physiol 2008, 215: 161-171

27. Juan SH, Lee JL, Ho PY, Lee YH, Lee WS: Antiproliferative and antiangiogenic effects of 3-methylcholanthrene, an aryl-hydrocarbon receptor agonist, in human umbilical vascular endothelial cells. Eur J Pharmacol 2006, 530:1-8

28. Yin KJ, Lee JM, Chen H, Xu J, Hsu CY: Abeta25-35 alters Akt activity, resulting in Bad translocation and mitochondrial dysfunction in cerebrovascular endothelial cells. J Cereb Blood Flow Metab 2005, 25: 1445-1455

29. Lin H, Lee JL, Hou HH, Chung CP, Hsu SP, Juan SH: Molecular mechanisms of the antiproliferative effect of beraprost, a prostacyclin agonist, in murine vascular smooth muscle cells. J Cell Physiol 2008 , 214:434-441

30. Shih CM, Lin H, Liang YC, Lee WS, Bi WF, Juan SH: Concentrationdependent differential effects of quercetin on rat aortic smooth muscle cells. Eur J Pharmacol 2004, 496:41-48

31. Lee $\mathrm{MH}$, Bell RM: Mechanism of protein kinase $\mathrm{C}$ activation by phosphatidylinositol 4,5-bisphosphate. Biochemistry 1991, 30:10411049

32. Vilimek D, Duronio V: Cytokine-stimulated phosphorylation of GSK-3 is primarily dependent upon PKCs, not PKB. Biochem Cell Biol 2006, $84: 20-29$

33. Gelfand BD, Meller J, Pryor AW, Kahn M, Bortz PD, Wamhoff BR, Blackman BR: Hemodynamic activation of beta-catenin and T-cellspecific transcription factor signaling in vascular endothelium regulates fibronectin expression. Arterioscler Thromb Vasc Biol 2010, 31:1625-1633 